Park, G.L. ; Schäfer, A.I. ; Richards, B.S. (2011)

The effect of wind speed fluctuations on the performance of a wind-powered membrane system for brackish water desalination,

Journal of Membrane Science (accepted 2/12/2010).

\section{Renewable Energy Powered Membrane Technology: The effect of wind speed fluctuations on the performance of a wind-powered membrane system for brackish water desalination}

Submitted to

rane Science

$$
2010
$$

Gavin L. Park ${ }^{\mathrm{a}}$, Andrea I. Schäfer ${ }^{\mathrm{b}}$, Bryce S. Richards ${ }^{\mathrm{a}}$

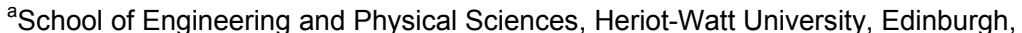
EH14 4AS, United Kingdom

${ }^{b}$ School of Engineering, The University of Edinburgh, Edinburgh, EH9 3JL, United Kingdom

* Corresponding author: Bryce S. Richards, E-mail: B.S.Richards@hw.ac.uk; Phone: +44 (0)131 4513614 , Fax: +44(0) 1314513129

\section{Abstract}

A wind-powered reverse osmosis membrane (wind-membrane) system without energy storage was tested using synthetic brackish water (2750 and $5500 \mathrm{mg} / \mathrm{L} \mathrm{NaCl}$ ) over a range of simulated wind speeds under both steady-state and fluctuating conditions. The parameters varied were: i) average wind speed from 3.7 (system start-up) to $8.7 \mathrm{~m} / \mathrm{s}$; ii) wind turbulence intensity from 0.0 (steady-state conditions) to 0.6 (extreme fluctuations); and iii) period of (sthe wind-membrane system oscillation from 15 to $90 \mathrm{~s}$. With a feed water of $2750 \mathrm{r}$ produced good-quality permeate $(<600 \mathrm{mg} / \mathrm{L})$ over the full range of wind speeds and fluctuations. The system performance (in terms of permeate flux and $\mathrm{NaCl}$ concentration) at average wind speeds of $7.0 \mathrm{~m} / \mathrm{s}$ or more was unaffected by fluctuations up to a turbulence intensity of 0.4 and was independent of the period of fluctuation within this operating range. With a feed water of $5500 \mathrm{mg} / \mathrm{L} \mathrm{NaCl}$ an average wind speed of $7.0 \mathrm{~m} / \mathrm{s}$ or more was required to produce adequate-quality permeate $(<1000 \mathrm{mg} / \mathrm{L})$ under fluctuating conditions. It is concluded that this wind-membrane system can be operated within a safe operating window with large power fluctuations, but further control strategies are required to deal with intermittent operation, especially with higher salinity feed waters.

Keywords: Power fluctuation; Intermittent operation; Wind energy; Reverse osmosis; Renewable energy

\section{Introduction}

Although the world is ahead of schedule for meeting the 2015 Millennium Development Goals target of halving the number of people without sustainable access to safe drinking water there are still 884 million people without access to improved water sources, $84 \%$ of which live in rural areas [1]. This problem is compounded by the fact that rural areas are generally not considered during central energy planning and 1.5 billion people have no access to electricity, $85 \%$ of which live in rural areas in developing countries [2]. There is a clear need for off-grid systems that can supply the necessary energy required to remove microbial and chemical pollutants. Groundwater is a good resource in these circumstances as there is relatively predictable long-term availability in the water table when compared to surface water and less risk of contamination from human and industrial waste. Renewable energy-powered (RO) are promising technologies (3] as (RO) are promising technologie for brackish water desalination in remote [4] and can be designed according to the water supply, number of inhabitants and energy resource.

The use of wind turbines for desalination has been proven to be economically feasible as wind technology is well advanced and coastal sites in particular often have a good wind resource [5]. The main challenges associated with the use of wind turbines are the intermittency and fluctuations of the wind resource which occur due to turbulence and gusts over short periods of time (seconds to a few minutes) and mass air movements over long periods of time (tens to hundreds of hours) [6]. The direct connection of a wind turbine to a $\mathrm{RO}$ system with no form of energy storage will inevitably result in large fluctuations in pressure and flow rate. This presents a considerable challenge for wind-powered membrane (wind-membrane) systems as membranes are designed to operate at constant operating (Wonditions with no abrupt prossure or cross-flow varigtions in order to minimize damage [7]. coniral wound RO modues have d7. Spiral wound volume ratio, increased robustness and permeability $[8,9]$. The challenges faced by these membranes are fouling and concentration polarization, which result in reduced flux and deterioration of permeate quality [8]. External fouling of membranes can be minimized by pretreatment, operating conditions and regular cleaning of the membranes [10]. In contrast, internal fouling, caused by physical compaction and chemical degradation, is largely irreversible and ultimately affects the lifetime of the membrane [10]. It is well known that introducing fluid instabilities in the region of concentration polarization will result in increased performance because the induced turbulence disturbs the polarization layer [11, 12]. AlBastaki et al. [13] performed experiments in which the pressure was varied according to an asymmetric square wave about a constant mean value as this produces the most abrupt disturbance in the boundary layer. The results showed that cyclic operation of this nature she increased with increasing amplitude and decreasing period of flucluation of the operating pressure [13]. This indicates that there could be possible benefits to be gained from the inherent fluctuations in a wind-membrane system, although there has been very little work performed in this area.

The majority of the small-scale (permeate production $\leq 25 \mathrm{~m}^{3} /$ day) wind-membrane systems that have been developed either use the electrical output from a horizontal axis wind turbin with energy storage in batteries [14-18], or the mechanical output from multi-vaned windmills with a pressure vessel as the buffer for fluctuations $[19,20]$. While the use of deep-cycle lead acid batteries can enable uninterrupted operation, they result in increased capital and 
Park, G.L. ; Schäfer, A.I. ; Richards, B.S. (2011)

The effect of wind speed fluctuations on the performance of a wind-powered membrane system for brackish water desalination,

Journal of Membrane Science (accepted 2/12/2010). operational costs as well as lower system efficiency [3] and decreased robustness [21]. There have been several wind-membrane systems that operated successfully under varying flow rate and pressure with no form of energy storage [22-27]; however the transient operation of these systems under fluctuation, and the extent to which these fluctuations can be managed or exploited is not well understood. There is a need for systematic investigation of the effect of fluctuations on membrane systems in order to understand the underlying mechanisms and determine their effect. Intermittent operation of RO systems has been shown to be undesirable because of the reduction in permeate quality due to lower flux combined with the continual diffusion of salt across the membrane $[25,28,29]$. Variable operation could also lead to mechanical fatigue and reduce both the life-time and performance of the membrane [26]. Some preliminary studies suggest that membranes can operate in a variable manner without deteriorating $[22,23]$, although the tolerable bandwidth of this variation has not been without det peen determined. $\mathrm{O}$ variable operation on $R O$ membecially at lower pressures $[3,26,30]$. Furthermore, the safe operating window in which fluctuations are beneficial or tolerable has not yet been determined.

Previous tests were performed using the RE-membrane system with six Zenon ZW10 ultrafiltration membranes (UF) for pre-treatment and four different nanofiltration or RO membranes with a real brackish groundwater $(5300 \mathrm{mg} / \mathrm{L}$ total dissolved solids (TDS) $8290 \mu \mathrm{s} / \mathrm{cm}$ ) using a constant power source [30]. The operating window of the system unde steady-state conditions (pressure from $4-12$ bar and feed flow rates 300,400 and $500 \mathrm{~L} / \mathrm{h}$ ) showed that safe operation could be achieved for this highly brackish groundwater with NF90, ESPA4 and BW30 membranes but not with TFC-S [30]. The system was further tested by direct connection (no energy storage) to a photovoltaic (PV) array (300 W from two $24 \mathrm{~V}_{\mathrm{DC}}$ pan s) over several solar days [3]. The results showed that the RE-membrane system (using panels) over several solar days [3]. The results showed that the RE-membrane system (using a Filmtec BW30-4040 element) operated und $1200 \mathrm{~W} / \mathrm{m}^{2}$ with minimal efect on the permeate quality, although further testing below $500 \mathrm{~W} / \mathrm{m}^{2}$ would be required to determition, the fluctuations shown over a typical solar day during these experiments [3] showed an average rate of change of $1 \%$ per second whilst wind fluctuations over a typical day were calculated to vary by $12 \%$ per second. This highlights the need for a separate study to investigate the effect of more severe variations in power which are associated with wind energy. In this pape a systematic investigation was conducted in order to determine the effect of wind speed fluctuations and intermittency on the performance of the wind-membrane system. Simulated oscillations in wind speed with variables of average wind speed, period of fluctuation and wind turbulence intensity were performed under controlled conditions using a programmable power supply and verified using a wind tunnel.

\section{Materials and Methods}

\subsection{Wind-membrane system set-up}

The wind-membrane system described here was a single-stage membrane system consisting of a 4WD double-axle trailer to house the membrane system and a free-standing transportable wind turbine described below. In this experimental setup (see Figure 1), the UF pre-treatment stage used in previous publications $[3,30]$ was replaced with a polypropylene $1 \mu \mathrm{m}$ micro filter with cartridge volume $1.2 \mathrm{~L}$ (SupaGard). A Filmtec BW30-4040 brackish water RO membrane [7] was used for all experiments. The micro filter was immersed in stainless steel feed tank (feed volume $130 \mathrm{~L}$ ) and permeate and concentrate flows were continuously recycled back into the feed tank in order to maintain a constant feed concentration and $\mathrm{pH}$ of 6.8 . An air bubbling system was used to ensure homogenous mixing and the temperature of the feed water was maintained at $13{ }^{\circ} \mathrm{C}$ by constant circulation through a water chiller system. This feed water temperature was chosen to reflect a typical groundwater temperature as would be found in regions with a temperate climate. The temperature of ground water responds to seasonal variations in the heat from the sun at depths of up to $25 \mathrm{~m}$ and is generally within $7^{\circ} \mathrm{C}$ of the mean annual air temperature whilst on average $1-2{ }^{\circ} \mathrm{C}$ higher [31]. The main power requirement was a $300 \mathrm{~W}$ progressive cavity pump that drew water through the micro filter (suction pressure of -0.3 bar) before pumping it through the RO membrane (up to 12 bar). In order to examine the effect of energy fluctuations, a set point was determined by the input power, pump motor speed and the regulating valve on the on the concentrate stream at the start of each experiment. The set point provided a system pressure of $10 \mathrm{bar}$ and a feed low rate of $300 \mathrm{~L} / \mathrm{h}$ under constant power operation at $240 \mathrm{~W}$. The pure water flux of thin the period of testing using this set point.

Figure 1

To accurately determine the transient operation of the system under fluctuations of this nature all of the parameters (pressure, flow rate, conductivity, temperature, $\mathrm{pH}$, current, voltage) were taken at a reading rate of $1 \mathrm{~Hz}$ using a datalogger (dataTaker DT800). A LabVIEW interface was used for viewing instantaneous system performance and downloading the data to a computer. Membrane specific parameters of transmembrane pressure (TMP, measured unless otherwise stated), flux $(J)$, recovery $(Y$, retention $(R)$ and specific energy consumption (SEC) were calculated using the relationships defined previously $[3,30]$. Electrical conductivity, $\mathrm{EC}(\mu \mathrm{S} / \mathrm{cm})$ was converted into $\mathrm{NaCl}(\mathrm{mg} / \mathrm{L})$ using a conversion factor $k=0.625$ as measured using $\mathrm{NaCl}$ dissolved in deionized water at $13^{\circ} \mathrm{C}$.

\subsection{Water quality and analysis}

Feed waters were prepared using deionized water and general purpose grade $\mathrm{NaCl}$ (Fisher Scientific, UK) with salinities of 2750 and $5500 \mathrm{mg} / \mathrm{L} \mathrm{NaCl}$. The conductivity of the feed, permeate and concentrate streams were measured using conductivity electrodes (GF Signet).

\subsection{Wind characteristics}

Wind speed variations consist of short-term fluctuations related to turbulence or gusts and longer term fluctuations due to large movements of air. Short term fluctuations caused by turbulence over time periods of up to an hour can vary significantly and are generally the most important for wind energy systems [32]. These fluctuations are taken to be the stochastic variations in wind speed averaged over a period of ten minutes [6]. Wind turbulence intensity (TI) is the basic measure of turbulence and can be seen as random wind speed fluctuations imposed on the mean wind speed. $\mathrm{TI}$ is represented as the dimensionless ratio (-) of the standard deviation of the wind speed to the mean wind speed [6]

$$
\mathrm{TI}=\frac{\sigma_{U}}{U}
$$

where $\sigma_{U}$ is the standard deviation of the wind speed $(\mathrm{m} / \mathrm{s})$ and $U$ is the short-term (over a ten minute period) mean wind speed $(\mathrm{m} / \mathrm{s})$, henceforth referred to as the average wind speed. TI 
is generally in the range of $0.1-0.4$, with the highest values occurring at the lowest wind speeds [6].

Wind speed fluctuations are often approximated by a sinusoidal wave in order to simplify practical experiments [25] and theoretical analysis [33]. The wind speed during a time period $v(t)$ is then defined as

$$
v(t)=U+A \sin \left(2 \pi \frac{t}{T}\right),
$$

where $A$ is the amplitude of fluctuation $(\mathrm{m} / \mathrm{s})$ and $T$ is the period of oscillation (s)

\subsection{Controlled fluctuations and intermittency}

An experimental plan was designed to take into account the random fluctuations of wind in a controlled manner in order to eliminate the uncontrolled variables and complexity inherent in real wind. To achieve this, a programmable power supply (Agilent Technologies E4350B) was used to provide power in the range $0-300 \mathrm{~W}$, corresponding to the power output of the wind turbine obtained at high wind speeds $(>13 \mathrm{~m} / \mathrm{s}$ ) and the rated power of the pump motor. The range of periods of oscillation, $T$ and length of time with no power were chos real wind fluctuations. Three main aspects of wind fluctuations were used;

real wind fluctuations. Three main aspects of wind fluctuations were used; Steady-state conditions: constant power experiments (Figure 2A) were used to determine the steady-state operating characteristics of the membrane system to form a baseline for comparison with results obtained with fluctuations. The power was held constant for 20 minutes during each step of $60,120,180,240$ and $300 \mathrm{~W}$, corresponding to average wind speeds of $3.7,5.3,7.0,8.7$ and $13.3 \mathrm{~m} / \mathrm{s}$, respectively.

2. Simulated fluctuations: oscillating power experiments (Figure $2 B$ ) lasted for a period of 10 minutes with the parameters of average power, peak-to-peak amplitude and period of oscillation varied one at a time to cover the full range of operation: i) average power from $60-240 \mathrm{~W}$; ii) peak-to-peak amplitude from $0 \mathrm{~W}$ (steady-state conditions) to $340 \mathrm{~W}$ (extreme fluctuations); and iii) period of oscillation from $15-90 \mathrm{~s}$.

3. Intermittent operation: power step experiments (Figure $2 \mathrm{C}$ ) were used to turn the power off for varying lengths of time and test the effect of off-time on permeate quality and system stabilzation time (dithed variables i) peak-to-peak amplitude from $60-300 \mathrm{~W}$ and ii) length of time with no power
for $0.5-3$ minutes. Sufficient time was given for the system parameters to return to their for $0.5-3$ minutes. Sufficient time was given
original values after each period of no power.

\section{Figure 2}

\subsection{Wind turbine characteristics and wind tunnel testing}

To assess system performance in real wind speed conditions experiments were conducted using the wind turbine (see Figure 1) in a wind tunnel whilst directly connected to the membrane system. The wind turbine (rated power $1 \mathrm{~kW}$ at $125 \mathrm{~m} / \mathrm{s}$. FuturEnergy) had five mencs a sive blades, a diacting the wind turbine to the membrane system is the main design challenge for a directlyconnected system. Having chosen the pump motor based on the required pressure and flow rates, the wind turbine must be sized to meet this demand according to the available wind resource and the wind turbine power curve. As mentioned previously, the wind resource is highly variable and very site specific. The fact that small wind turbines are placed on low towers means they experience much lower average wind speeds and are susceptible to turbulence because of obstacles and frictional effects. Another challenge is that there is no standard method that manufacturers are required to follow in order to measure the power curve and wind turbines are often rated at high wind speeds that are rarely experienced in the field. This makes it very difficult to accurately predict performance without actually testing the wind turbine and using high resolution wind speed data. This wind turbine was selected based on the power requirements of the pump motor and associated electronics, as well as the performance and relative cost of the wind turbine [35]. The pump motor was a permanent magnet brushless DC motor rated at $300 \mathrm{~W}$ with maximum voltage and current of $180 \mathrm{~V}_{\mathrm{DC}}$ and $3 \mathrm{~A}$, respectively. The electronics included a maximum power point tracker (inputs: $30-$ $100 V_{D C}, 0-5 A$ ) to maximise the power output from a $48 V_{D C}$ photovoltaic array, and the required controller for the brushless DC motor. A five-bladed wind turbine was chos chosen due to the improved performance at lower wind speeds as a result of the higher torque generated with more blades (See Section 3.1., for further details). The wind tunnel (TUV NEL, East Kilbride, UK) had a cross section of $3.2 \mathrm{~m}$ (width) $\times 3 \mathrm{~m}$ (height) and could produce wind speeds of up to $13.3 \mathrm{~m} / \mathrm{s}$ using a bank of nine fans that could be switched selectively in orde to create controlled fluctuations in wind speed. The wind speed in the tunnel was measured using a cup anemometer (A100L2, Vector Instruments) that was placed $1.5 \mathrm{~m}$ upstream of the wind turbine rotor

Wind speeds were held for a period of twenty minutes before being increased in steps $(3.7$ $5.3,7.0,8.7,10.1,11.7,13.3 \mathrm{~m} / \mathrm{s}$ ) by increasing the speed of the fans in the wind tunnel. $A$ range of wind turbulence intensities from $0.3-0.6$ were tested at average wind speeds of 3.7 5.3, 7.0, 8.7 and $10.1 \mathrm{~m} / \mathrm{s}$ within the constraints of the wind tunnel (maximum wind speed $13.3 \mathrm{~m} / \mathrm{s}$ ). The experiments were performed over ten minutes (standard length of time used in wind turbulence measurements) with an oscillation period of $30 \mathrm{~s}$, and repeated once for wind turbulence 政 Section 2.4 in order to allow direct comparison.

The relationship between $\mathrm{TI}$ and the peak-to-peak amplitude used in the experiments described in Section 2.4 is illustrated in Figure 3. The peak-to-peak amplitude varied linearly with the $\mathrm{TI}$ until the power constraint of the pump motor $(300 \mathrm{~W})$ was exceeded.

Figure 3

\subsection{Determination of safe operating window}

The safe operating window is essential to ascertain that a water treatment is operating efficiently and is performing the task for which it was designed; to remove the contaminants from the water. In order to analyse the operation of the mem from the war subject to fluctuations of pressure and flow rate, a new measure of peformance was developed. This was necessary because fluctuations in power resulted in rapid changes in the flux whilst the permeate quality took longer to respond due to diffusion. Using the permeate quality as the main performance indicator does not take into account the periods of low flux when the permeate quality may be good but in reality the system is not operating effectively. The proposed usability index (UI) is dimensionless (-) and equates good system performance to a high flux with a permeate stream that meets the required guideline value for a particular chemical or contaminant as defined by the following relationship,

$$
\mathrm{UI}=\left(\frac{\mathrm{J}}{\mathrm{J}_{0}}\right) \times\left(\frac{C_{\text {guideline }}-C_{\text {permeate }}}{C_{\text {guideline }}}\right),
$$


Park, G.L. ; Schäfer, A.I. ; Richards, B.S. (2011)

The effect of wind speed fluctuations on the performance of a wind-powered membrane system for brackish water desalination,

Journal of Membrane Science (accepted 2/12/2010).

where $C$ is concentration $(\mathrm{mg} / \mathrm{L})$. The $\mathrm{UI}$ has a maximum value of 1 (when passing deionized water through the system) and depending on the solutes involved, will generally be in the range of $-1 \leq U \mid \leq 1$. A Ul of $O$ indicates that there is no flux, whereas a negative value shows that the concentration of the permeate stream is not compliant with the guideline value and the system is functioning outside the safe operating window. For the present work, $J_{0}$ was $25 \mathrm{~L} / \mathrm{m}^{2} . h$ and the solute of interest was sodium chloride $(\mathrm{NaCl})$, with a WHO guideline value of $1000 \mathrm{mg} / \mathrm{L}$ [36]. The $\mathrm{Ul}$ is a useful indicator of system performance but should be used in conjunction with the SEC for a more detailed analysis of the operating window.

\section{Results and Discussion}

\subsection{Power performance of wind turbine and membrane system}

The main aims of this study were to determine the effect of wind speed fluctuations on the performance of the wind turbine and the extent to which these can be beneficial or detrimental within a safe operating window. A power curve showing the relationship between wind speed and power output from the wind turbine was determined using the wind tunnel (Figure 4). Up to a wind speed of $7 \mathrm{~m} / \mathrm{s}$ the relationship of power output with wind speed was linear. At higher wind speeds a combination of wind turbine furling and the power restrictions of the pump motor caused the wind turbine power curve to level off at a maximum value of $300 \mathrm{~W}$. The difference between the two power curves was caused by the control electronics between the wind turbine and the pump motor which have an average efficiency of $86 \%$. Wind turbine furling is a self-protection mechanism that turns the blades out of the wind during high winds to avoid excest $8.7 \mathrm{~m}$ s and above which was much lower than expecte $8.7 \mathrm{~m} / \mathrm{s}$ and above, which was much lower than expected based on the rated power given by the manufacturer $(1 \mathrm{~kW})$ and resulted in much less power being generated. The constan resistance curve in Figure 4 illustrates why this particular wind turbine was chosen. A low cut in wind speed $(2.3 \mathrm{~m} / \mathrm{s})$ was observed as a result of the high torque generated with having five blades as opposed to three. Importantly, this resulted in much more energy being produced at low wind speeds when compared with other small wind turbines. A resistance of $10 \Omega$ is shown as this best represented the load of the membrane system and illustrates that the power generated was a good match for this pump motor. However, the resistance of the membrane system changed with the power available as shown by the mismatch between the curves. This was most evident at wind speeds above $7 \mathrm{~m} / \mathrm{s}$ where the wind turbine curve departed from the constant resistance curve due to the higher load from the pump motor which varied in the range $10-25 \Omega$.

Figure 4

\subsection{Operating characteristics under steady-state conditions}

The operation of the membrane system under steady-state conditions served as a baseline for comparison with fluctuations in power. The TMP (Figure $5 \mathrm{~A}$ ) increased with wind powe and was independent of the concentration of the feed water as it was controlled by the valve on the concentrate stream which was set at the start of each experiment. This was a nonlinear relationship and was seen to level off above $240 \mathrm{~W}$ due to lower efficiency in the region of the rated power of the pump motor $(300 \mathrm{~W})$. It should be noted that the effective TMP reduced by the osmotic pressure in the membrane boundary layer and was therefore dependent on the salt concentration of the feed as well as operating conditions. The effective TMP reduction due to the osmotic pressure of the feed water was calculated as 2.2 bar for $2750 \mathrm{mg} / \mathrm{L}$ and 4.4 bar for $5500 \mathrm{mg} / \mathrm{L}$ without taking into account the effect of concentration polarization.

Figure 5

At low pressure, permeate flux and recovery are controlled by mass transfer mechanisms and therefore exhibit a linear dependence on the effective TMP [9]. The flux (Figure $5 \mathrm{~B}$ ) and the recovery (Figure $5 \mathrm{C}$ ) both followed the same trend as the TMP. The values of flux and recovery were lower for the higher feed concentration due to the lower effective TMP mentioned above. In order to validate this, the osmotic pressure was subtracted from the TMP to give the effective TMP and the flux calculated to be equal to the effective TMP multiplied by a constant $(C=1.96)$ for both feed waters. This relationship only holds true at the low pressures shown here where the effects of concentration polarization are insignificant. The retention (Figure $5 \mathrm{D}$ ) increased with the available power to a maximum value of $92 \%$ for both of the feed waters at $180 \mathrm{~W}$ with $2750 \mathrm{mg} / \mathrm{L} \mathrm{NaCl}$ and $300 \mathrm{~W}$ with $5500 \mathrm{mg} / \mathrm{L} \mathrm{NaCl}$. The retention was below the expected value according to the manufacturer due to the operating conditions and the age of the membrane, which was used for field trials in Australia in 2005 [3 30] and for extensive laboratory experiments since then. Whilst the flux was consistent with previous experiments, the maximum retention under these operating conditions has reduced from $96 \%$ [37] to $92 \%$ over time (Figure $5 \mathrm{D}$ ). It should be noted that increasing the feed water temperature would result in higher flux and lower retention due to the increased rate of diffusion of water and salts through the membrane. Analysis of this membrane using modelled data (ROSA 7.2. Dow Water and Process Solutions) showed a $10 \%$ increase in flux and $1 \%$ data (ROSA 7.2, Dow Water and Process Solutions) showed a $10 \%$ increase in flux and $1 \%$ reduction in retention when the feed water temperature was increased from $13-25^{\circ} \mathrm{C}$ (Table 1). The permeate $\mathrm{NaCl}$ (Figure $5 \mathrm{E}$ ) decreased with increasing power and leveled of at a minimum value of $226 \mathrm{mg} / \mathrm{L}$ and $466 \mathrm{mg} / \mathrm{L}$ with feed waters of $2750 \mathrm{mg} / \mathrm{L}$ and $5500 \mathrm{mg} / \mathrm{L}$ $\mathrm{NaCl}$, respectively. As would be expected, the concentrate $\mathrm{NaCl}$ (Figure $5 \mathrm{~F}$ ) followed the opposite relationship to the permeate and increased with the available power. With respect to a safe operating window, the permeate $\mathrm{NaCl}$ (Figure $5 \mathrm{E}$ ) was within the $\mathrm{WHO}$ guideline value over the full range of operating conditions with a feed water of $2750 \mathrm{mg} / \mathrm{L} \mathrm{NaCl}$. With a feed water of $5500 \mathrm{mg} / \mathrm{L} \mathrm{NaCl}$, a minimum of $120 \mathrm{~W}$ (TMP of $6.6 \mathrm{bar}$ ) was required to produce permeate within the guideline value. The SEC (Figure $5 \mathrm{G}$ ) exhibited high values at low power as most of the energy was used to overcome the osmotic pressure and little permeate was produced. This decreased to a minimum value of $1.6 \mathrm{kWh} / \mathrm{m}^{3}(2750 \mathrm{mg} / \mathrm{L})$ and $2.8 \mathrm{kWh} / \mathrm{m}^{3}$ $(5500 \mathrm{mg} / \mathrm{L})$ before increasing again at high power. The minimum value was achieved for the two feed waters at a flux of $8 \mathrm{~L}^{2} \mathrm{~m}^{2} \mathrm{~h}$, after which the SEC increased due to the pump opering wo 8 efficiency above $240 \mathrm{~W}$. It can therefore be concluded that the most energy efficient operating point for the mith a feed water of $2750 \mathrm{mg} / \mathrm{L} \mathrm{NaCl}$ and at $180 \mathrm{~W}$ with a feed of $5500 \mathrm{mg} / \mathrm{L}$. The pump moto efficiency was calculated as the ratio of the hydraulic power to the electrical power input and included the efficiency of the brushless DC motor $(85 \%)$. There was a reduction in the efficiency observed with the higher feed water salinity due to the increased density of the feed water. The maximum efficiency of $\sim 44 \%$ was achieved at $180 \mathrm{~W}$ for both feed waters. The $U$ (Figure $5 \mathrm{H}$ ) achieved a maximum value of 0.51 and 0.23 for the feed waters of $2750 \mathrm{mg} / \mathrm{L}$ and $5500 \mathrm{mg} / \mathrm{L} \mathrm{NaCl}$, respectively. The low values of $\mathrm{Ul}$ obtained with a feed water of 5500 $\mathrm{mg} / \mathrm{L} \mathrm{NaCl}$ show that the system was operating within the guideline value but with higher 
Park, G.L. ; Schäfer, A.I. ; Richards, B.S. (2011)

The effect of wind speed fluctuations on the performance of a wind-powered membrane system for brackish water desalination,

Journal of Membrane Science (accepted 2/12/2010).

concentration and lower permeate flux (Figure $5 \mathrm{~B}$ ) when compared to a $2750 \mathrm{mg} / \mathrm{L}$ feed water.

It should be noted that the Filmtec BW30-4040 module is being operated below the test conditions given by the manufacturer [7]. This is because systems designed to operate in remote regions with renewable energy have different design criteria to those used for conventional systems. Rather than designing for the maximum water flux with high pressure, recovery and salt rejection, the most important factors for designing these systems are the energy requirements and robust long term operation [20]. The energy required determines the size of the renewable energy generator which translates directly into the capital cost of the system. As a result, smaller pumps are used which also generate lower flow rates and pressure. The effect of operating conditions on the energy required was determined using the membrane system analysis software provided by the manufacturer (ROSA 7.2) as shown in Table 1 . If a larger pump was obtained with the same efficiency, then the power required in Table 1. ditions given by the manufacturer would be $2520 \mathrm{~W}$ with an SEC of $6.6 \mathrm{kWh} / \mathrm{m}^{3}$ using a feed of $2000 \mathrm{mg} / \mathrm{L}$. In order to operate the system at $15.5 \mathrm{ba}$ and $15 \%$ recovery using a feed water of $5500 \mathrm{mg} / \mathrm{L}, 1840 \mathrm{~W}$ would be required and a flux of $38.2 \mathrm{~L} / \mathrm{m}^{2}$.h would be produced with an SEC of $6.7 \mathrm{kWh} / \mathrm{m}^{3}$. This would require a much large wind turbine at significant cost when compared to the maximum value of $300 \mathrm{~W}$ required for operating the system in these experiments. It should be noted that larger systems may have more energy efficient pumps and employ energy recovery (generally at higher pressure) which would result in much lower SEC. The situation shown here is unique to brackish wate systems where energy recovery is not really feasible due to the relatively low pressures used. The data in Table 1 also illustrates the effect of operating conditions on the UI. By using lower feed concentrations at higher pressure and feed flow rate, the UI approaches unity. However the cost of operating at the prent conergy required.

\subsection{Effect of simulated fluctuations (sine wave oscillations in power)}

Figure 6 shows the operation of the membrane system with a feed water of $2750 \mathrm{mg} / \mathrm{L}$ under controlled fluctuations using an oscillating power supply with two different periods of oscillation (15 and $90 \mathrm{~s}$ ), constant peak-to-peak amplitude of $200 \mathrm{~W}$ (equivalent $\mathrm{TI}=0.4$ ) and average power of $120 \mathrm{~W}$ (equivalent average wind speed $=5.3 \mathrm{~m} / \mathrm{s}$ ). The high amplitude shown here caused the power to switch off at longer periods as the slower oscillation in powe allowed the TMP to drop to a lower level, putting a high load on the pump. The combination of high load and slowly oscillating power resulted in insufficient power to regain the system pressure and the system shut down periodically. Figure 6 A illustrates that the power did not onger periods of low power resulted in the minimum start-up power was 4 bar (Figure $6 \mathrm{~A}$ ), fluctuations down to 3 bar (Figure $6 \mathrm{~B}$ ) occurred once operational within the safe operating window. The on/off switching of the pump at a period of $90 \mathrm{~s}$ caused significant deterioration in performance as demonstrated by the long periods of no flux (Figure $6 \mathrm{C}$ ) and recovery (Figure $6 \mathrm{D}$ ) and the higher average permeate $\mathrm{NaCl}$ (Figure $6 \mathrm{E}$ ). The average retention (Figure $6 \mathrm{~F}$ ) observed at a period of $15 \mathrm{~s}$ was $87 \%$ which compared well with the steady state value of $91 \%$ (Figure $5 \mathrm{D}$ ). However the longer period of oscillation caused the average retention to drop to $82 \%$ (Figure $6 \mathrm{~F}$ ). The SEC (Figure $6 \mathrm{G}$ ) exhibited a large spike when the system was switched on due to the power required to achieve the flux required for desalination. This resulted in higher average SEC a $90 \mathrm{~s}$ period because of the power shutting off. The average UI (Figure $6 \mathrm{H}$ ) whilst water was being produced was slightly higher at $90 \mathrm{~s}$ period than at $15 \mathrm{~s}$, but this was offset by the amount of time with no productivity.

Figure 6

The full range of experiments performed with feed waters of $2750 \mathrm{mg} / \mathrm{L}$ and $5500 \mathrm{mg} / \mathrm{L} \mathrm{NaCl}$ and variables of equivalent average wind speed, $\mathrm{TI}$ and period of oscillation are given as supplementary data in tabular form. In order to better understand the combined effects of these variables, the data for $2750 \mathrm{mg} / \mathrm{L}$ from the supplementary data is illustrated in Figure 7 as the $\mathrm{UI}$. As mentioned in the introduction, there is evidence that fluctuations may result in increased flux compared to steady-state conditions as a result of disturbances in the polarization layer [11-13]. The results of this study (Figure 7) showed that there was no increase obtained in the flux under fluctuating with steady-state conditions $(\mathrm{TI}=0)$. The exception to this was at low average wind speeds (Figure $7 \mathrm{~A}$ ) fo reasons discussed below. The flux at low TI was consistent with that obtained under steady state conditions and was seen to drop at higher TI once the power started cycling on/off. In contrast, studies in the literature that have exhibited increased flux were performed at average pressures of 40 and 50 bar with amplitudes of 5 to 10 bar using a feed water of $10,000 \mathrm{mg} / \mathrm{L} \mathrm{NaCl}$ and showed a maximum increase of $13 \%$ in the permeate flux [13] Therefore, from this study, it is hypothesised that there was no increase observed in the flux because of the reduced effects of concentration polarization at the relatively low pressures and feed water salinities used. Although Figure $7 \mathrm{~A}$ shows that fluctuations at low average wind speeds can result in better system performance than under steady-state conditions $(\mathrm{TI}=0.0)$, it was because the fluctuations provided additional power and the system stayed turned on because of the rapid fluctuations. The effect of the power switching off at low turned caused the power to switch off at lower values of TI resulting in a significantly reduced UI.

\section{Figure 7}

The performance of the system is easily understood at higher average wind speeds (Figures $7 \mathrm{C}$ and $7 \mathrm{D}$ ) where the $\mathrm{Ul}$ is independent of the period Higher $\mathrm{Tl}$ caused the system to start shutting off as shown by the drop in $\mathrm{UI}$ at 0.5 . The rise in $\mathrm{UI}$ shown at $\mathrm{TI}$ of 0.6 was due to the additional amplitude of fluctuation providing more power to the system which reduced the stabilization time (explained below). At wind speeds highe than $7.0 \mathrm{~m} / \mathrm{s}$, the fluctuations had little effect up to a TI of 0.4 which indicates that the system could operate as if under steady-state conditions under real wind speeds of $7.0 \mathrm{~m} / \mathrm{s}$ or more It should be noted that the wind-membrane system produced water within the guideline value over the 作 7 A-D. Wh show in Figure $7.0 \mathrm{~m}$. Wr wind speed of $7.0 \mathrm{~m} / \mathrm{s}$ or more in order to operate within the safe operating window and there was zero flux produced under all fluctuations at the lowest average wind speed of $3.7 \mathrm{~m} / \mathrm{s}$. Fluctuations at low average wind speeds caused the TMP to remain below 4 bar for significant periods of time and resulted in zero flux due to the higher osmotic pressure of this feed water. As mentioned above (Section 3.2.), the osmotic pressure of the feed waters was calculated as $2.2 \mathrm{bar}$ for $2750 \mathrm{mg} / \mathrm{L}$ and 4.4 bar for $5500 \mathrm{mg} / \mathrm{L}$. 
Park, G.L. ; Schäfer, A.I. ; Richards, B.S. (2011)

The effect of wind speed fluctuations on the performance of a wind-powered membrane system for brackish water desalination,

Journal of Membrane Science (accepted 2/12/2010).

3.4. Effect of intermittent operation

As a final step in characterizing the performance of the system under real wind speed fluctuations, the effect of the power cycling on/off was investigated to simulate intermitten operation. Whilst the extreme fluctuations dealt with above are more commonly found in wind power, intermittence is a characteristic of all renewable energy resources and it is importan to understand its effect on the membrane system to determine the operating window. Following a period of no power, a spike in the permeate $\mathrm{NaCl}$ was observed upon re-starting the system due to the diffusion of salts across the membrane during the period of no flux. The net flux of $\mathrm{NaCl}$ across the membrane from the feed to the permeate during periods of $n$ power a 0.46 mater of $2750 \mathrm{mg} / \mathrm{L}$ and $0.87 \mathrm{mg} / \mathrm{m}^{2} . \mathrm{s}$ for a feed water of $5500 \mathrm{mg} / \mathrm{L}$. The the required for the permeate $\mathrm{NaCl}$ to return to its original value once the permeate flow had resumed was called the stabilization time. It should be noted that the permeate $\mathrm{NaCl}$ achievable depended on the power available as shown in Figure $5 \mathrm{E}$, therefore the stabilization time (Figure 8) was the time taken to return to the original value. Figure 8 demonstrates that the stabilization time depended upon both the amount of power available to re-start the system and the feed concentration. The amount of power available determined the TMP, flow rate and resulting flux which purged the system of the high salinity permeate; therefore more power resulted in less time required for purging. The volume of water that remained in the membrane vesse and must be purged was measured as $2 \mathrm{~L} \pm 10 \%$. The feed concentration affected the stabilization time as the higher feed concentration reduced the effective TMP and resulting flux due to higher osmotic pressure. The effect of feed concentration is demonstrated in for 5500 mg/L $5500 \mathrm{mg} / \mathrm{L}$.Cl with $240 \mathrm{~W}$ of power while only $120 \mathrm{~W}$ was required to achieve stability this time with a feed water of $2750 \mathrm{mg} / \mathrm{L} \mathrm{NaCl}$. The impact on the permeate concentration could be minimised by ensuring that sufficient power is available following a period of shutdown. For a feed water of $2750 \mathrm{mg} / \mathrm{L} \mathrm{NaCl}$, the system could operate with up to three minutes of down-time without the permeate exceeding the WHO guideline value. With a feed water of $5500 \mathrm{mg} / \mathrm{L} \mathrm{NaCl}$ the minimum power required to produce permeate of adequate quality after a period of down-time was $120 \mathrm{~W}$, and this must be sustained last for at least five minutes (Figure 8). Depending on the frequency of intermittent operation and the length of time with no power, it may be acceptable to allow the $2 \mathrm{~L}$ of high salinity permeate produced to mix with the rest of the good quality permeate that is stored. As these results have shown this would depend very much upon the wind resource available and the salinity of the feed water.

Figure 8

\subsection{System performance with wind turbine in wind tunnel}

The wind-membrane system was tested with the wind turbine in the wind tunnel for two main reasons: i) to determine the effect of real fluctuations and ii) to verify the results of the experiments performed with the programmable power supply. Figure $9 \mathrm{~A}-\mathrm{H}$ shows the system operating close to its limit in terms of the maximum amplitude of fluctuations, at an average wind speed of $U=5.3 \mathrm{~m} / \mathrm{s}$ and wind turbulence intensity of $\mathrm{TI}=0.4$ with a feed water of $2750 \mathrm{mg} / \mathrm{L} \mathrm{NaCl}$. The results showed that fluctuations in power (Figure $9 \mathrm{~B}$ ) were due to complex relationship of wind speed fluctuations (Figure $9 A$ ), furling of the wind turbine and high loading from the membrane system at start-up. As shown in Figure $9 \mathrm{~B}$, the result was that the wind turbine power did not always follow the pattern of the wind speed. The TMP (Figure $9 \mathrm{C}$ ) varied according to the magnitude of power and the length of time for which it was available as well as the TMP starting point. Once the power was switched off, the TMP exhibited an exponential decay which assisted in absorbing the longer term fluctuations $(>15 \mathrm{~s})$ but not the short-term ones $(<10 \mathrm{~s})$. The main effect of these fluctuations was the greatly reduced flux (Figure $9 \mathrm{D}$ ) which averaged $4.2 \mathrm{~L} / \mathrm{m}^{2} . \mathrm{h}$, less than half the steady-state value of $8.8 \mathrm{~L} / \mathrm{m}^{2}$.h obtained at the same average power (Figure $5 \mathrm{~B}$ ). Both the flux (Figure $9 \mathrm{D}$ ) and the recovery (Figure $9 \mathrm{E}$ ) demonstrated that the periods where the powe was switched on compared favourably with the steady-state conditions shown in Figure $5 \mathrm{~B}$ and $5 \mathrm{C}$, but the periods of no power resulted in greatly reduced average system performance. In contrast, the permeate $\mathrm{NaCl}$ was much less affected by these fluctuations. Even under a high level of fluctuation at a low average wind speed, the permeate remained well with in the guideline value (Figure $9 \mathrm{~F}$ ). The combination of a the minute period of well with (Fig hopower (Fin on/of below a TMP the guideline value. A time lag was observed between the pressure drop and the increase in $\mathrm{NaCl}$ due to the time of no-power and the time taken for diffusion of salts across the membrane. The performance of the system with regards to water quality is also shown by the average retention (Figure $9 \mathrm{G}$ ) of $85 \%$ observed during this period which compared very well with the steady-state retention of $91 \%$ (Figure $5 \mathrm{D}$ ) at the same average power. Because of the high $\mathrm{TI}$ and subsequent shutting on/off, the SEC averaged over the seven minute period was $0.7 \mathrm{kWh} / \mathrm{m}^{3}$ with peaks of up to up to $3.4 \mathrm{kWh} / \mathrm{m}^{3}$ (Figure $9 \mathrm{H}$ ). This was similar to the value of $1.6 \mathrm{kWh} / \mathrm{m}^{3}$ observed under steady-state conditions but illustrates how frequent turning on/off resulted in increased energy consumption. This is further highlighted by the effect of fluctuating power on the efficiency of the pump motor. The average pump moto efficier (not plotted) was $33 \%$, significantly low than the $44 \%$ measured under steadyefficiency (not por state conditions (see Figure $5 \mathrm{H}$ ). As observed in Figure $9 \mathrm{~A}$, the main effect of these large wind speed fluctuations was the reduced flux. Over short periods of ten minutes, the largest wind fluctuations resulted in a $50 \%$ reduction in productivity when compared to steady-state conditions even though the permeate was within the guideline value. It should be noted that these fluctuations are at the extreme end of what any system would experience in practice. This reduction in productivity is only an indication and a long term trial would be required to determine what the overall effect of fluctuations on productivity is compared to steady-state conditions. These results verify the conclusion from the laboratory based experiments that the wind-membrane system can operate under large wind speed fluctuations and intermittence within a safe operating window.

Figure 9

\section{Conclusions}

The operation of a wind-membrane system with no form of energy storage is described under simulated and real wind speed fluctuations from controlled experiments using a programmable power supply and a wind tunnel. In terms of a safe operating window, the membrane system was shown to produce good-quality drinking water with a feed water of $2750 \mathrm{mg} / \mathrm{L} \mathrm{NaCl}$ over the whole range of operation with wind speeds from $3.7 \mathrm{~m} / \mathrm{s}$ (system start-up) to $8.7 \mathrm{~m} / \mathrm{s}$ at turbulence intensities 0.0 (steady-state condidions) to 0.6 (extreme fluctuations) and periods of oscillation from $15-90 \mathrm{~s}$. With a feed water of $5500 \mathrm{mg} / \mathrm{L}$, the 
performance was much more marginal with wind speeds of $7.0 \mathrm{~m} / \mathrm{s}$ or more required to produce adequate-quality permeate under fluctuating conditions. The operation of the membrane system was influenced by the average wind speed as well as the TI (directly related to the amplitude of fluctuations) and the period of oscillation. However, at average wind speeds of $7.0 \mathrm{~m} / \mathrm{s}$ or higher the performance was independent of the period of oscillation up to a TI of 0.4 . In addition, within this operating range the system performance was the same under fluctuations as under steady-state conditions. The system performance was seen to deteriorate most under fluctuations that occured at low average wind speeds with high T and long periods of oscillation. These types of fluctuations allowed the power to shut off and the low average wind speeds meant that there was insufficient power available for the system pressure to recover to a suitable level. For system stabilization to occur after a period of nopower the important factor was the amount of power available to re-start the system rather pown the length of down-time. This is an interesting result if shorterm the system rathe than the length of down buffering is to be considered as it reduces the requirement of having the system running constantly and the emphasis is shifted to the amount of power avallable to restart the system. This work demonstrates that membrane systems can be directly connected to renewable energy systems (wind power presents the most extreme fluctuations) and operate effectively within a safe operating window. The main challenge associated with operation of this nature is not the size of the fluctuations but the effect of the power switching off which causes reduced flux and permeate quality. This must be controlled in innovative ways by energy buffering careful control of the water treatment load or disposal of the poor quality permeate in order for RE-membrane systems to be utilised. The membrane system has been operated for $>250$ hours under large fluctuations in power without any noticeable effect on the components or the operation of the membrane. Further testing would be necessary to determine the effect of long term operation of this nature.

\section{Acknowledgements}

The PhD studentship for Gavin L. Park is provided by the Joint Research Institute in Energy, part of the Edinburgh Research Partnership in Engineering and Mathematics. We would like to thank Scottish Enterprise for funding the use of their wind tunnel facility at the Energy Technology Centre and TUV NEL for their technical support and consultation throughout the period of testing. We thank Ronald Millar and Curtis Abbott for their technical support throughout this project and Laura Richards for proof reading

\section{Supplementary data available}

Detailed results on the performance of the membrane system under oscillating power for feed waters of $2750 \mathrm{mg} / \mathrm{L}$ and $5500 \mathrm{mg} / \mathrm{L} \mathrm{NaCl}$ are given in terms of flux $\left(\mathrm{L} / \mathrm{m}^{2} . \mathrm{h}\right)$ and permeate $\mathrm{NaCl}(\mathrm{mg} / \mathrm{L})$ in Tables S1 and S2. This information will be available alongside the electronic version of this article in Elsevier Web products at http://www.sciencedirect.com.

\section{References}

11] Department of Economic and Social Affairs, The Millennium Development Goals Report United Nations, New York, 2009, pp. 46
[2] A. Niez, Comparative study on rural electrification policies in emerging economies, International Energy Agency, 2010.

[3] B.S. Richards, D.P.S. Capão, A.I. Schäfer, Renewable Energy Powered Membrane Technology. 2. The Effect of Energy Fluctuations on Performance of a Photovoltaic Hybrid Membrane System, Environmental Science \& Technology, 42 (2008) 4563-4569.

[4] M.A. Shannon, P.W. Bohn, M. Elimelech, J.G. Georgiadis, B.J. Marinas, A.M. Mayes, Science and technology for water purification in the coming decades, Nature, 452 (2008) 301-310.

[5] M. Forstmeier, F. Mannerheim, F. D'Amato, M. Shah, Y. Liu, M. Baldea, A. Stella, Feasibility study on wind-powered desalination, Desalination, 203 (2007) 463-470.

[6] J.F. Manwell, Wind Energy Explained: Theory, Design and Application, John Wiley \& Sons Ltd, 2002.

[7] Dow Water Solutions, Membrane datasheet Filmtec BW30-4040; $\mathrm{http}: / / \mathrm{www}$.dowwaterandprocess.com/products/membranes/bw30 4040.htm (18 November 2010).

[8] J. Schwinge, P.R. Neal, D.E. Wiley, D.F. Fletcher, A.G. Fane, Spiral wound modules and spacers: Review and analysis, Journal of Membrane Science, 242 (2004) 129-153.

[9] L. Song, J.Y. Hu, S.L. Ong, W.J. Ng, M. Elimelech, M. Wilf, Performance limitation of the full-scale reverse osmosis process, Journal of Membrane Science, 214 (2003) 239-244.

[10] E.M.V. Hoek, J. Allred, T. Knoell, B.-H. Jeong, Modeling the effects of fouling on full-scale reverse osmosis processes, Journal of Membrane Science, 314 (2008) 33-49.

[11] H.B. Winzeler, G. Belfort, Enhanced performance for pressure-driven membrane processes: the argument for fluid instabilities, Journal of Membrane Science, 80 (1993) 3547.

[12] N. Al-Bastaki, A. Abbas, Use of fluid instabilities to enhance membrane performance: a review, Desalination, 136 (2001) 255-262.

[13] N.M. Al-Bastaki, A. Abbas, Periodic Operation of a Reverse Osmosis Water Desalination Unit, Separation Science and Technology, 33 (1998) $2531-2540$.
Un 254 .

[14] D. Infield, Performance analysis of a small wind powered reverse osmosis plant, Solar Energy, 61 (1997) 415-421.

[15] E.S. Mohamed, G. Papadakis, Design, simulation and economic analysis of a standalone reverse osmosis desalination unit powered by wind turbines and photovoltaics, Desalination, 164 (2004) 87-97.

[16] G. Petersen, S. Fries, J. Mohn, A. Muller, Wind and solar powered reverse osmosis desalination units - design, start up, operating experience, Desalination, 39 (1981) 125135.

[17] E. Tzen, D. Theofilloyianakos, M. Sigalas, K. Karamanis, Design and development of a hybrid autonomous system for seawater desalination, Desalination, 166 (2004) 267-274

[18] D. Weiner, D. Fisher, E.J. Moses, B. Katz, G. Meron, Operation experience of a solarand wind-powered desalination demonstration plant, Desalination, 137 (2001) 7-13.

19] C.C.K. Liu, P. Jae-Woo, R. Migita, Q. Gang, Experiments of a prototype wind-driven

[19] C.C.K. Liu, P. Jae-Woo, R. Migita, Q. Gang, Experiments of a prototype wind-driven
reverse osmosis desalination system with feedback control, Desalination, 150 (2002) 277287.

[20] R. Robinson, G. Ho, K. Mathew, Development of a reliable low-cost reverse osmosis desalination unit for remote communities, Desalination, 86 (1992) 9-26.

[21] M. Thomson, M.S. Miranda, D. Infield, A small-scale seawater reverse-osmosis system with excellent energy efficiency over a wide operating range, Desalination, 153 (2003) 229-236. 
Park, G.L. ; Schäfer, A.I. ; Richards, B.S. (2011)

The effect of wind speed fluctuations on the performance of a wind-powered membrane system for brackish water desalination,

Journal of Membrane Science (accepted 2/12/2010).

[22] I. de la Nuez Pestana, F. Javier Garcia Latorre, C. Argudo Espinoza, A. Gomez Gotor, Optimization of RO desalination systems powered by renewable energies. Part I: Wind energy, Desalination, 160 (2004) 293-299.

[23] W. Gocht, A. Sommerfeld, R. Rautenbach, T. Melin, L. Eilers, A. Neskakis, D. Herold, V. Horstmann, M. Kabariti, A. Muhaidat, Decentralized desalination of brackish water by directly coupled reverse-osmosis-photovoltaic-system - a pilot plant study in Jordan, Renewable Energy, 14 (1998) 287-292.

[24] S.G.J. Heijman, E. Rabinovitch, F. Bos, N. Olthof, J.C. van Dijk, Sustainable seawater desalination: Stand-alone small scale windmill and reverse osmosis system, Desalination, 248 (2009) 114-117.

[25] E.R. Lising, R. Alward, Unsteady State Operation of a Reverse-Osmosis Desalination Unit, Desalination, 11 (1972) 261-268.

[26] M.S. Miranda, D. Infield, A wind-powered seawater reverse-osmosis system without batteries, Desalination, 153 (2003) 9-16.

[27] F. Moreno, A. Pinilla, Preliminary experimental study of a small reverse osmosis windpowered desalination plant, Desalination, 171 (2005) 257-265.

[28] M. Thomson, D. Infield, Laboratory demonstration of a photovoltaic-powered seawater reverse-osmosis system without batteries, Desalination, 183 (2005) 105-111.

[29] R. McBride, R. Morris, W. Hanbury, Wind power a reliable source for desalination, Desalination, 67 (1987) 559-564.

[30] A.I. Schäfer, A. Broeckmann, B.S. Richards, Renewable Energy Powered Membrane Technology. 1. Development and Characterization of a Photovoltaic Hybrid Membrane System, Environ. Sci. Technol., 41 (2007) 998-1003.

[31] R.C. Heath, Basic Ground-Water Hydrology, U.S. Geological Survey Water-Supply Paper 2220, (1983)

[32] P.D. Lund, J.V. Paatero, Energy storage options for improving wind power quality, Nordic Wind Power Conference, Espoo, Finland, 2006

[33] A. Rosen, Y. Sheinman, The power fluctuations of a wind turbine, Journal of Wind Engineering and Industrial Aerodynamics, 59 (1996) 51-68.

[34] FuturEnergy Ltd, FuturEnergy $1 \mathrm{~kW}$ datasheet;

http://www.futurenergy.co.uk/FE1048U\%20(408).pdf (19 November 2010).

[35] G.L. Park, A.I. Schäfer, B.S. Richards, Potential of wind-powered renewable energy membrane systems for Ghana, Desalination, 248 (2009) 169-176.

[36] World Health Organization, Guidelines for Drinking-water Quality, WHO press, 2008

37] L. Masson, B.S. Richards, A.I. Schäfer, System design and performance testing of a hybrid membrane -- photovoltaic desalination system, Desalination, 179 (2005) 51-59.
Table 1 Analysis of simulated system performance using manufacturer's standard test conditions (2000 mg/L NaCl; applied pressure 15.5 bar; $25{ }^{\circ} \mathrm{C} ; 15 \%$ recovery) and the test conditions contained in this work compared to experimental results. Simulation was performed assuming constant pump efficiency (ROSA 7.2, Dow Water and Process Solutions).

\begin{tabular}{|c|c|c|c|c|c|}
\hline \multirow[t]{2}{*}{ Parameter } & \multicolumn{4}{|c|}{ Simulation } & \multirow{2}{*}{$\begin{array}{c}\text { Experimen } \\
5500 \mathrm{mg} / \mathrm{L}\end{array}$} \\
\hline & $\begin{array}{l}\text { Standard } \\
\text { test } \\
\text { conditions }\end{array}$ & $\begin{array}{c}5500 \mathrm{mg} / \mathrm{L} \\
\text { feed and } \\
\text { standard } \\
\text { test } \\
\text { conditions } \\
\end{array}$ & $\begin{array}{c}5500 \mathrm{mg} / \mathrm{L} \\
\text { feed and our } \\
\text { test } \\
\text { conditions } \\
\left(\text { at } 25^{\circ} \mathrm{C}\right) \\
\end{array}$ & $\begin{array}{c}5500 \mathrm{mg} / \mathrm{L} \\
\text { feed and our } \\
\text { test } \\
\text { conditions } \\
\left(\text { at } 13^{\circ} \mathrm{C}\right) \\
\end{array}$ & \\
\hline \multicolumn{6}{|l|}{ Inputs } \\
\hline Pre-stage $\Delta \mathrm{P}$ (bar) & -0.9 & -0.9 & -0.24 & -0.24 & -0.24 \\
\hline Feed $\mathrm{NaCl}(\mathrm{mg} / \mathrm{L})$ & 2000 & 5500 & 5500 & 5500 & 5500 \\
\hline Feed temp. $\left({ }^{\circ} \mathrm{C}\right)$ & 25 & 25 & 25 & 13 & 13 \\
\hline Feed flow (L/h) & 2530 & 1750 & 300 & 300 & 300 \\
\hline Feed pressure (bar) & 15.5 & 15.5 & 10 & 10 & 10 \\
\hline Pump efficiency (\%) & 43.2 & 43.2 & 43.2 & 43.2 & 43.2 \\
\hline \multicolumn{6}{|l|}{ Outputs } \\
\hline Permeate flow $(\mathrm{L} / \mathrm{h})$ & 380 & 280 & 101 & 77 & 75 \\
\hline Flux (L/m².h) & 52.4 & 38.2 & 14.1 & 10.7 & 10.4 \\
\hline Retention (\%) & 99.4 & 99.2 & 97.6 & 98.7 & 91.3 \\
\hline Recovery (\%) & 15 & 15 & 33.9 & 26.0 & 25.4 \\
\hline Power (W) & 2520 & 1840 & 190 & 190 & 210 \\
\hline $\operatorname{SEC}\left(\mathrm{kWh} / \mathrm{m}^{3}\right)$ & 6.6 & 6.7 & 1.9 & 2.5 & 2.8 \\
\hline UI (-) & 0.84 & 0.59 & 0.49 & 0.40 & 0.22 \\
\hline
\end{tabular}


Park, G.L. ; Schäfer, A.I. ; Richards, B.S. (2011)

The effect of wind speed fluctuations on the performance of a wind-powered membrane system for brackish water desalination,

Journal of Membrane Science (accepted 2/12/2010).

\section{List of figures}

Figure 1 Schematic diagram of the wind-membrane system with electrical connections (dotted lines) and water flow (solid lines) for the components of the wind-membrane system: programmable power supply; wind turbine; motor controller; micro filter; RO membrane; pump; P1 - P3: pressure transducers; F1 - F3: flow sensors; C1 - C3: conductivity sensors V1 - V2: voltage sensors; I1 - I2: current sensors; $\mathrm{pH} / \mathrm{T}$ : $\mathrm{pH}$ and temperature sensor.

Figure 2 Power inputs to experiments performed on the wind-powered membrane system using a programmable power supply; A: steady-state conditions; B: simulated fluctuations and C: intermittent operation.

Figure 3 Relationship between $\mathrm{TI}$ and the peak-to-peak amplitude of power oscillation used in experiments with the programmable power supply.

Figure 4 Wind turbine power curve at constant load and with the wind turbine connected to membrane system.

Figure 5 Steady-state performance of the wind-membrane system using constant power from a programmable power supply for feed waters of 2750 and $5500 \mathrm{mg} / \mathrm{L} \mathrm{NaCl}$ plotted as A: transmembrane pressure (TMP); B: flux; C: recovery D: retention of $\mathrm{NaCl}$ (observed); $\mathrm{E}$ : permeate $\mathrm{NaCl}$; $\mathrm{F}$ : concentrate $\mathrm{NaCl}$; $\mathrm{G}$ : specific energy consumption (SEC); $\mathrm{H}$ : pump motor efficiency and I: usability index (UI).

Figure 6 Wind-membrane system performace using oscillating power (programmable power supply) for oscillation periods of $90 \mathrm{~s}$ and $15 \mathrm{~s}$ with a feed water of $2750 \mathrm{mg} / \mathrm{L} \mathrm{NaCl}$ (average power $180 \mathrm{~W}$, amplitude $200 \mathrm{~W}$ ).

Figure 7 Variation of average usability index (UI) with increasing wind turbulence intensity (TI) using oscillating power (programmable power supply) for oscillation periods of $15,30,45,60$, 75 and $90 \mathrm{~s}$ with a feed water of $2750 \mathrm{mg} / \mathrm{L} \mathrm{NaCl}$ at equivalent average wind speeds; A:

$3.7 \mathrm{~m} / \mathrm{s} ; B: 5.3 \mathrm{~m} / \mathrm{s} ;$ C: $7.0 \mathrm{~m} / \mathrm{s}$ and D: $8.7 \mathrm{~m} / \mathrm{s}$

Figure 8 Stabilization time of the permeate stream after a period of no power as a function of wind turbine power for feed waters of 2750 and $5500 \mathrm{mg} / \mathrm{L} \mathrm{NaCl}$

Figure 9 Performance of the wind-membrane system as a function of time using real wind speed fluctuations (wind tunnel) with a feed water of $2750 \mathrm{mg} / \mathrm{L} \mathrm{NaCl}$.
Figure 1

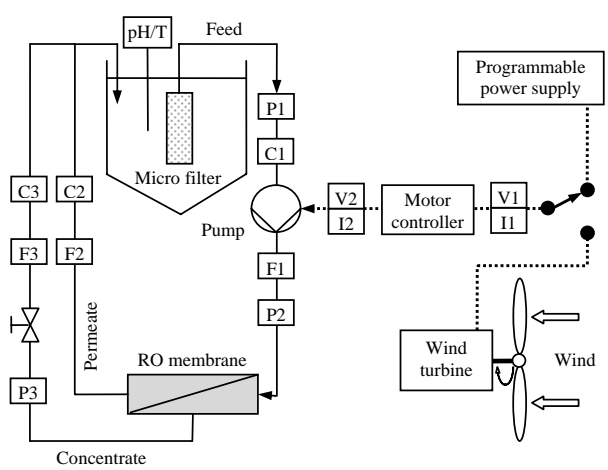


Park, G.L. ; Schäfer, A.I. ; Richards, B.S. (2011)

The effect of wind speed fluctuations on the performance of a wind-powered membrane system for brackish water desalination

Journal of Membrane Science (accepted 2/12/2010).

\section{Figure 2}

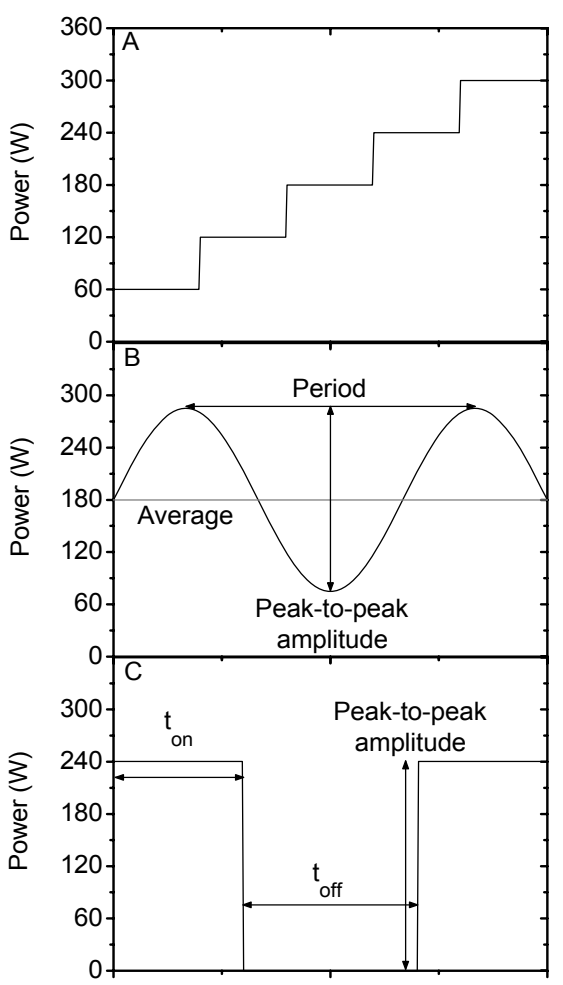

Time (min)
Figure 3

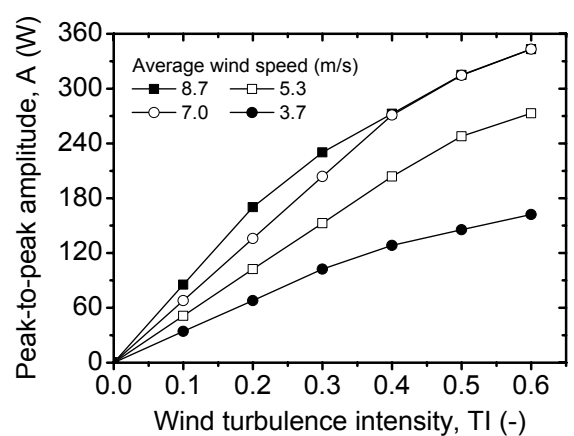


Park, G.L. ; Schäfer, A.I. ; Richards, B.S. (2011)

The effect of wind speed fluctuations on the performance of a wind-powered membrane system for brackish water desalination,

Journal of Membrane Science (accepted 2/12/2010).

Figure 4

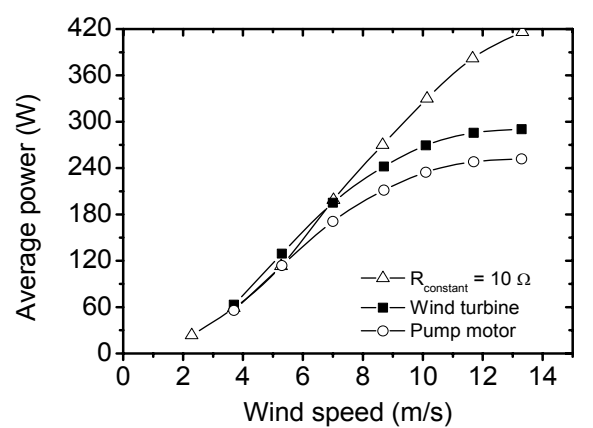

Figure 5
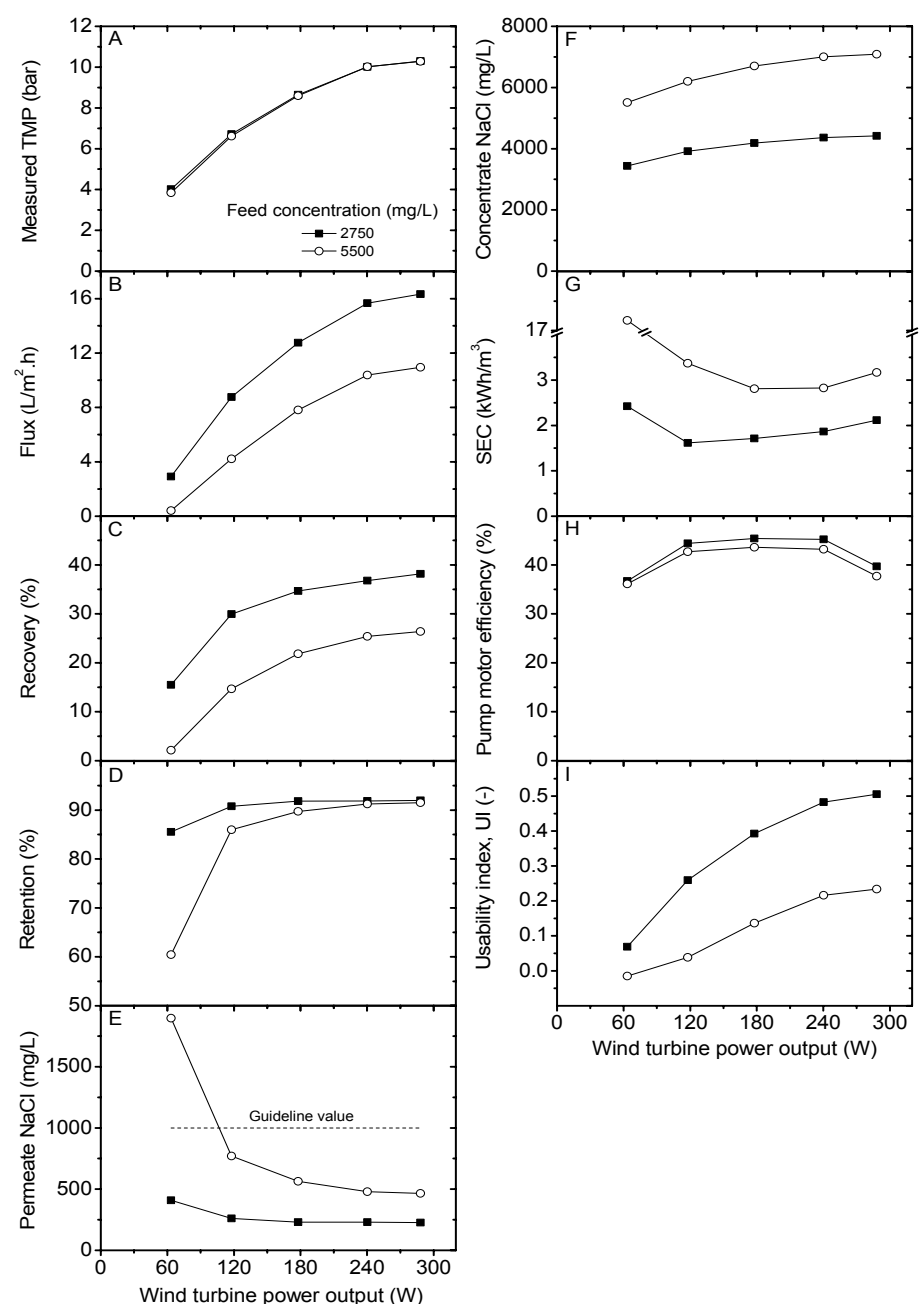
Park, G.L. ; Schäfer, A.I. ; Richards, B.S. (2011)

The effect of wind speed fluctuations on the performance of a wind-powered membrane system for brackish water desalination,

Journal of Membrane Science (accepted 2/12/2010).

Figure 6
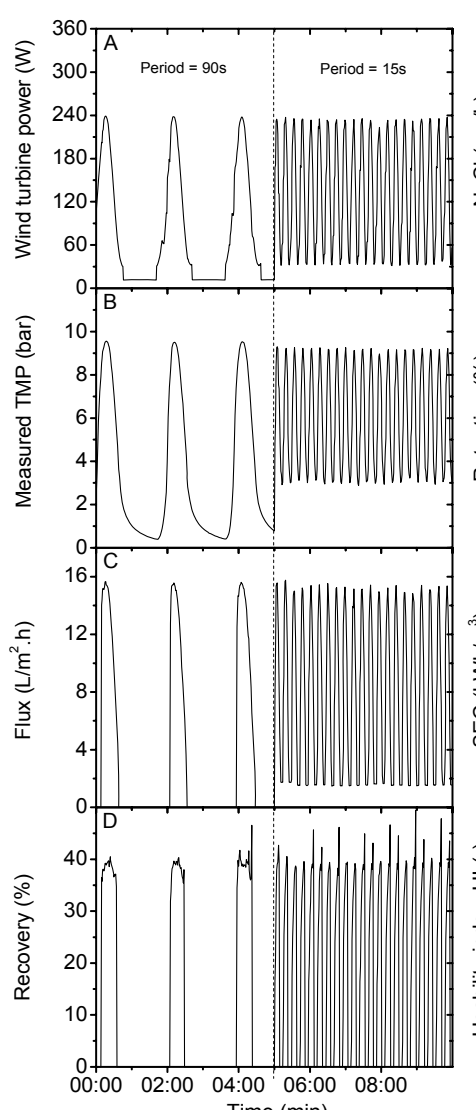

Time (min)

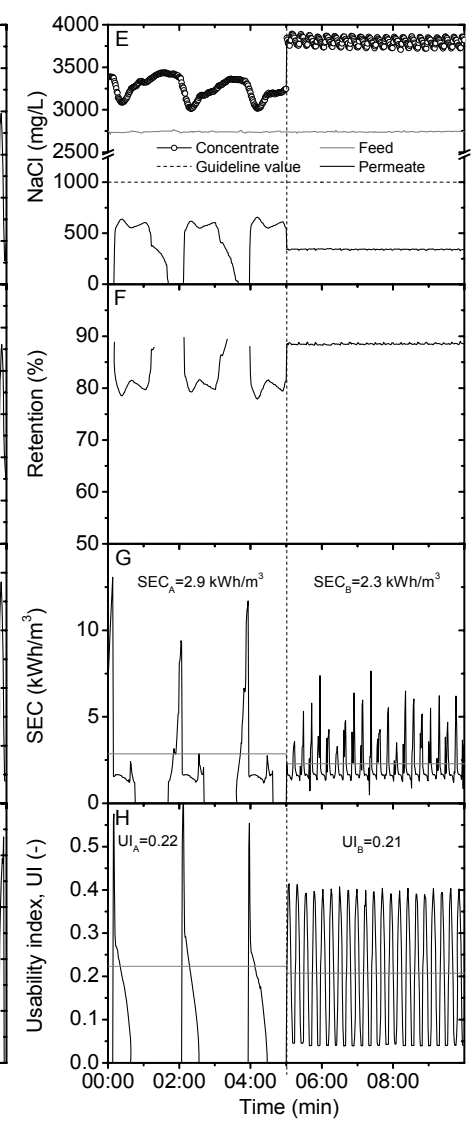

Figure 7

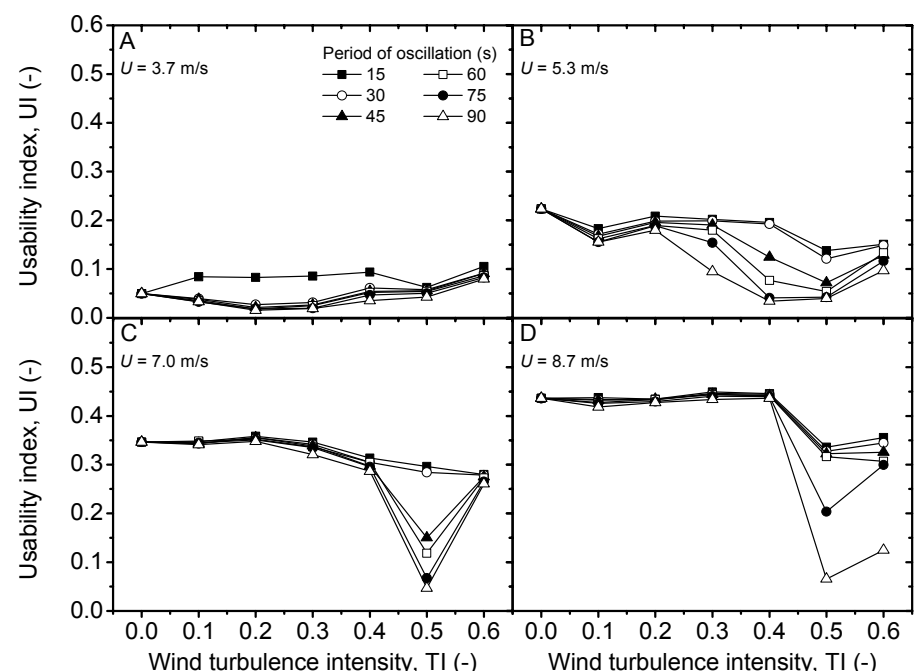


Park, G.L. ; Schäfer, A.I. ; Richards, B.S. (2011)

The effect of wind speed fluctuations on the performance of a wind-powered membrane system for brackish water desalination,

Journal of Membrane Science (accepted 2/12/2010).

Figure 8

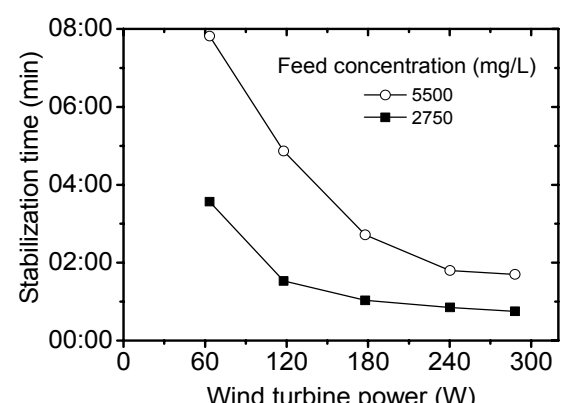

Figure 9
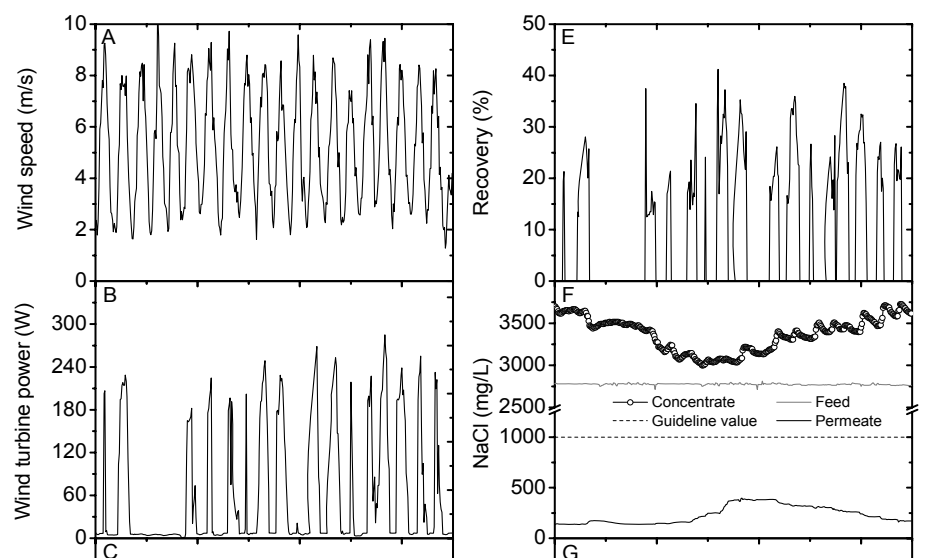

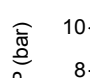

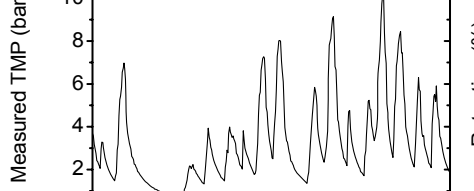

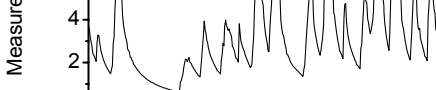
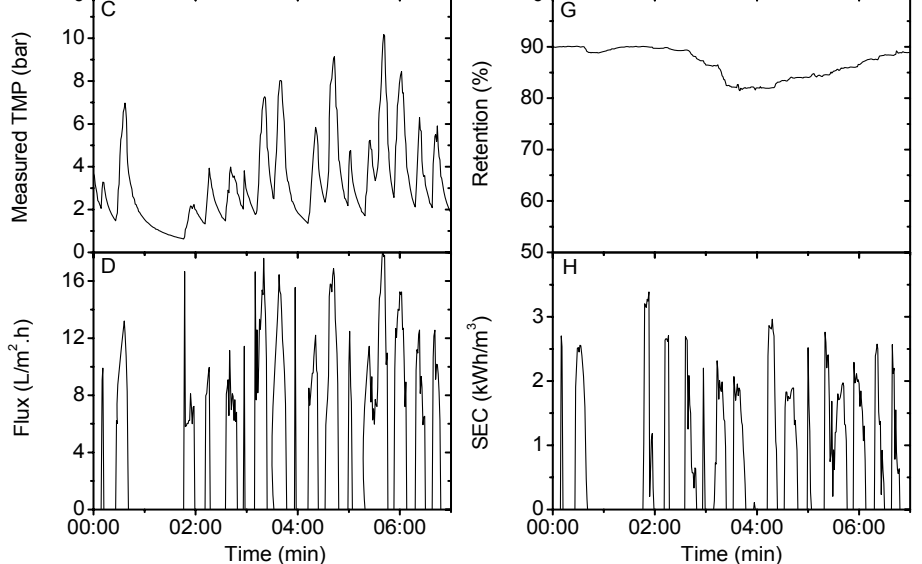